\title{
The Case for Investing in Typhoid Vaccines
}

Typhoid fever is a major cause of morbidity, with an estimated global incidence of 21,650,974 newcases, and 216,510 deaths, as of 2000 (1). Caused by Salmonella enterica subspecies enterica serotype Typhi (S. Typhi) and Paratyphi, this waterborne and foodborne infection has an annual incidence approaching 1\% in endemic areas (2-4). Historically, surveillance studies have reported peak incidences among children aged 5-15 years. However, recent investigations in South Asia (4-6) and elsewhere in the region $(7,8)$ reported high rates of infection among young children, with young age identified as a risk factor for infection.This has led to a re-assessment of the burden and the need for effective vaccination strategies for young preschool children (9). A driving force for vaccination, apart from the burden of disease, is the mounting concern over rising drug resistance (10).

Despite evidence of the high burden of typhoid fever by both S. enterica serovar Typhi and Paratyphi throughout Asia and sub-Saharan Africa (1) and public demand in endemic countries (9), most developing countries do not have a vaccination programme or policy. Several factors have contributed to this, including concerns over competing costs in developing countries (9).

In this issue of JHPN, Cook et al. ask three basic questions: (a) would a programme providing vaccine free of charge to users pass a social benefits test; (b) would that vaccine be a wise use of publicsector resources; (c) if the vaccine satisfies question 1 and 2, how can it be financed? (11). The latter is perhaps the most relevant to developing countries and is often the most challenging from a practical standpoint.

The authors then provide an economic analysis, highlighting the benefit of public expenditure for typhoid Vi polysaccharide vaccine using three met-

Correspondence and reprint requests should be addressed to:

Dr. W. Abdullah Brooks

Scientist, Infectious Diseases Unit

Health Systems and Infectious Diseases Division ICDDR,B

GPO Box 128, Dhaka 1000

Bangladesh

Email: abrooks@icddrb.org

Fax: +880-2-8826050 rics of economic benefit: private and public cost-ofillness (COI) avoided; avoided COI plus mortality risk-reduction benefits; and willingness-to-pay. This represents a more rigorous set of measurements than many conventional analyses of health economics and was conducted on sites that currently host ongoing studies on typhoid fever.

In addressing these three questions, the authors examined three potential vaccination scenarios: vaccination of all enrolled school children; vaccination of all children; and vaccination of adults and children. Addressing the first question, 'would a vaccine programme that dispensed Vi vaccine free of charge pass a social cost-beneift test?', they found that, restricting economic benefits to 'treatment costs avoided', none of the vaccination strategies would pass a social cost-benefit test. They point out, however, that the definition of treatment cost avoided is not only restrictive but likely underestimates true costs that are important to people, such as pain and suffering. Importantly, benefits, such as indirect protection to non-vaccinated persons, are not factored into the social cost-benefit analysis but are no less important.

However, when the authors used the common standard of cost per disability-adjusted life-year (DALY), they found that all the three strategies would be 'very cost-effective'. Importantly, at a cost of just over US\$ 1, they found that a typhoid-vaccination programme would absorb one-sixth of public-sector health spending in India (on a per-capita basis). This addressed the second question, 'would such a programme be a wise use of public-sector resources?', and that appears to be yes, it would.

Addressing the third question, the authors provide a more qualified answer. Drawing upon figures of public and private spending for health services in India, they argue that there is scope for the Government of India to share the cost of vaccination with a growing wealthier class. At a modest cost of US\$ 1.07 per vaccinated person, any of the three vaccination strategies would then absorb nearly a sixth of current per-capita public-health spending. In short, at a modest cost, the wealthier households could subsidize a portion of the cost for lower-income households.

They conclude that, given substantial private de- 
mand for typhoid vaccine, the Indian Government could employ user-fees to create a sustainable vaccination programme. Importantly, were adults to pay a higher user-fee, this could subsidize vaccines for children, who bear a higher burden of typhoid, which, in turn, would further reduce the number of new incident cases than would a flat user-fee and that this would still remain financially sustainable.

This is a timely paper, given the very recent evidence documenting the benefit of polysaccharide $\mathrm{Vi}$ vaccine in children aged two years or older in Kolkata, India, showing an $80 \%$ protective effectiveness in children aged 2-5 years, with a $44 \%$ indirect protective effect on non-vaccinated persons for an overall $57 \%$ protective effectiveness to the whole community (12). This vaccine trial, in which members of the current economic analysis took part, strongly substantiated the potential impact and value of routine typhoid fever vaccination in an endemic urban setting.

In light of the growing spread of typhoid fever, particularly in urban centres throughout the developing world, but especially in Asia, and the spread of antimicrobial resistance among Salmonella species, with its attendant treatment failure and increase in cost of care, a vaccination programme for typhoid fever would seem to be an obvious choice. Faced too with the evidence of disproportionate burden of disease among children, including those aged less than five years, any vaccination programme must offer direct benefit and relief to young children. A take-home message from this analysis is that the sustainability of such a programme may ultimately hinge less on economic or even clinical metrics than on the community-mindedness of those at risk, and the willingness of a few to make a small sacrifice for the benefit of the whole.

\section{REFERENCES}

1. Crump JA, Luby LS, Mintz ED. The global burden of typhoid fever. Bull World Health Organ 2004;82:34653.

2. Engels EA, Falagas ME, Lau J, Bennish ML. Typhoid fever vaccines: a meta-analysis of studies on efficacy and toxicity. BMJ 1998;316:110-6.

3. Simanjuntak CH, Paleologo FP, Punjabi NH, Darmowigoto R, Soeprawoto, Totosudirjo H et al. Oral immunisation against typhoid fever in Indonesia with Ty21a vaccine. Lancet 1991;338:1055-9.

4. Sinha A, Sazawal S, Kumar R, Sood S, Reddaiah VP, Singh B et al. Typhoid fever in children aged less than 5 years. Lancet 1999;354:734-7.

5. Brooks WA, Hossain A, Goswami D, Nahar K, Alam $\mathrm{K}$, Ahmed $\mathrm{N}$ et al. Bacteremic typhoid fever in children in an urban slum, Bangladesh. Emerg Infect Dis 2005;11:326-9.

6. Luby SP, Faizan MK, Fisher-Hoch SP, Syed A, Mintz ED, Bhutta ZA et al. Risk factors for typhoid fever in an endemic setting, Karachi, Pakistan. Epidemiol Infect 1998;120:129-38.

7. Yang MT, Chi CS. Salmonella infections in infants and children. Zhonghua Yi Xue Za Zhi (Taipei) 1994;54:3843.

8. Yap YF, Puthucheary SD. Typhoid fever in children-a retrospective study of 54 cases from Malaysia. Singapore Med J 1998;39:260-2.

9. World Health Organization. Meeting of the Immunization Strategic Advisory Group of Experts, November 2007-conclusions and recommendations. Wkly Epidemiol Rec 2008;83:1-15.

10. Rowe B, Ward LR, Threlfall EJ. Multidrug-resistant Salmonella typhi: a worldwide epidemic. Clin Infect Dis 1997;24(Suppl 1):S106-9.

11. Cook J, Sur D, Clemens J, Whittington D. Evaluating investments in typhoid vaccines in two slums in Kolkata, India. J Health Popul Nutr 2009;27:711-24.

12. Sur D, Ochiai RL, Bhattacharya SK, Ganguly NK, Ali M, Manna B et al. A cluster-randomized effectiveness trial of Vi typhoid vaccine in India. $N$ Engl J Med 2009;361:335-44.

\section{W. Abdullah Brooks}

Infectious Diseases Unit

Health Systems and Infectious Diseases Division

ICDDR,B

GPO Box 128, Dhaka 1000

Bangladesh 